\title{
Application of virtual reality on non-drug behavioral management of short-term dental procedure in children
}

\author{
Longkuan Ran ${ }^{1,2,3 \dagger}$, Nan Zhao ${ }^{1,2,3 \dagger}$, Lin Fan ${ }^{1,2,3}$, Pinping Zhou ${ }^{1,2,3}$, Chao Zhang ${ }^{1,2,3}$ and Cong Yu ${ }^{1,2,3^{*}}$ (D)
}

\begin{abstract}
Background: Due to the inherent characteristics of immersion, imagination, and interactivity in virtual reality (VR), it might be suitable for non-drug behavior management of children in dental clinics. The purpose of this trial was to measure the role of VR distraction on behavior management in short-term dental procedures in children.

Methods: A randomized clinical trial design was carried out on 120 children aged between 4 and 8 years to identify the comparative efficacy of VR and tell-show-do (TSD) to improve behavioral management during dental procedures. The primary outcomes were evaluated anxiety, pain, and compliance scores in perioperative children. The levels of operative anxiety and pain were assessed using the Children's Fear Survey Schedule-Dental Subscale (CFSS-DS) and Wong Baker FACES Pain Rating Scale (WBFS), respectively. The Frankl Behavior Rating Scale (FBRS) was tested before and during dental procedures. The length of the dental procedure was compared between both groups after treatment.
\end{abstract}

Results: The average anxiety and behavioral scores of the VR group significantly reduced compared with the control. The decreased anxiety score for the VR group and control group were $8(7,11)$ and $5(5,7), p<0.05$. The compliance scores of the control group during treatment were $3(2,3)$, and the same in the VR intervention were 3 $(3,4), p=0.02$. A significant reduction in pain was observed when using VR distraction $(p<0.05)$. Comparing the length of the dental procedure, the VR group (19.0 $2 \pm 5.32 \mathrm{~min}$ ) had a shorter treatment time than the control group (27.80 $\pm 10.40 \mathrm{~min})$.

Conclusion: The use of VR significantly reduced the anxiety and pain of children and the length of the dental procedure and improved the compliance of children that underwent short-term dental procedures without an adverse reaction.

Trial registration: Chinese Clinical Trial Registry, ChiCTR2000029802. Registered on February 14, 2020

Keywords: Virtual reality, Dental anxiety, Pain, Short-term dental procedure

\footnotetext{
* Correspondence: 500158@hospital.cqmu.edu.cn

Longkuan Ran and Nan Zhao made a common contribution.

'Department of Anesthesiology, Stomatological Hospital of Chongqing

Medical University, Chongqing, China

${ }^{2}$ Chongqing Key Laboratory of Oral Diseases and Biomedical Sciences,

Chongqing, China

Full list of author information is available at the end of the article
}

(c) The Author(s). 2021 Open Access This article is licensed under a Creative Commons Attribution 4.0 International License, which permits use, sharing, adaptation, distribution and reproduction in any medium or format, as long as you give appropriate credit to the original author(s) and the source, provide a link to the Creative Commons licence, and indicate if changes were made. The images or other third party material in this article are included in the article's Creative Commons. licence, unless indicated otherwise in a credit line to the material. If material is not included in the article's Creative Commons licence and your intended use is not permitted by statutory regulation or exceeds the permitted use, you will need to obtain permission directly from the copyright holder. To view a copy of this licence, visit http://creativecommons.org/licenses/by/4.0/ The Creative Commons Public Domain Dedication waiver (http://creativecommons.org/publicdomain/zero/1.0/) applies to the data made available in this article, unless otherwise stated in a credit line to the data. 


\section{Introduction}

Successful behavioral management might be related to the following two variables: anxiety, which is a psychological state and can be modified and controlled with psychological techniques, and pain, which is an unpleasant sensory and emotional experience [1]. For children's cognition levels during a dental procedure, it is necessary to conduct behavioral management; therefore, the children can cooperate with the pediadontist to complete the treatment.

In Southwest China, a substantial proportion of children that require dental care are unable to collaborate well with doctors and nurses due to dental anxiety (DA). The increase in pain, tension, and fear-related behaviors during dental procedures was defined as DA; it can be expressed as rapid heart rate, muscle tension, and even syncope [2]. DA refers to a universal level of stress that is characteristic of an individual and might have a constant level during the life span. The emotion interferes significantly with personal daily life, career development, or relationships. Various studies found that the incidence of DA was 20-43\%, which depended on the age of the child. In a recent survey, DA produced the majority of clinical problems in pediatric dental treatment [3].

For the treatment of DA, drugs were generally used in the Department of Anesthesiology of Stomatological Hospital affiliated to Chongqing Medical University (Yubei District, Chongqing, China), such as nitrous oxide $\left(\mathrm{N}_{2} \mathrm{O}\right)$ and sevoflurane. The $\mathrm{N}_{2} \mathrm{O}$ sedation can only be applied for patients that score three or four on the Frankl Behavior Rating Scale (FBRS) [4, 5]. Because the children are awake and have no other way to distract their attention, many children do not cooperate with pedodontists during a dental procedure. The child's parents might be concerned about possible damage from sevoflurane inhalation anesthesia, because the children and their families need to carry out general anesthesiarelated preoperative preparation: waiting for the appointment, fasting and drinking, risk of apnea, and recovery after anesthesia. Therefore, some children did not receive timely treatment, which results in lifelong poor oral health, and can cause long-term psychological trauma [6]. Therefore, timely and effective management of DA is central to improving the mental and physical health of children with oral diseases.

Virtual reality technology (VR) creates a highly realistic virtual, three-dimensional (3D) environment that provides various sense stimulate (e.g., sense of vision, sense of hearing, touch, and sense of smell) for the user to escape the real world [7, 8]. By stimulating visual, auditory, and proprioceptive sensations, VR acts as a distraction to interfere with the patient's handling of noxious stimuli [8]. In the last decades, VR has been applied to different healthcare settings. In particular, VR has reported in many clinical trials, such as trauma rehabilitation $[9,10]$, are of burns $[11,12]$, cancer treatment [13], operation training [14], and weight-related disorders [15]. Sato and Sarig-Bahat performed VR on complex regional pain syndromes [16] and chronic neck pain [17].

The analgesic effects of VR distraction reduce negative emotions (i.e., anxiety) and lead to positive emotions [18]. In some studies, VR distraction has been used to relieve pain and anxiety [7, 8, 11, 19-23]. Similarly, VR has been used as a distraction intervention to relieve pain during the perioperative period in dental surgery $[19,23]$. The application of VR technology in the behavioral management of children's dental procedures is limited. In addition, recent reports have stated that it reduces pain and anxiety in the dental setting and procedures [24, 25], but only for single dental procedures and the suitable duration of the treatment involved needs to be explored. In this study, the role of VR in the nondrug behavioral management of children is measured with short-term and simple dental procedures.

\section{Methods}

\section{Setting and patients}

This randomized clinical trial recruited 120 preschoolers aged 4-8 years who came to the Stomatological Hospital of Chongqing Medical University for dental treatment. This study followed the Declaration of Helsinki on medical protocol and ethics and the Regional Ethical Review Board of the Stomatological Hospital of Chongqing Medical University approved the trial.

\section{Inclusion criteria}

Consenting children (aged 4-8 years, ASA I-II) with a Children's Fear Survey Schedule-Dental Subscale (CFSSDS) questionnaire $>19$ [26]. The time of the dental procedure (caries treatment, extraction of deciduous teeth, incision of abscess, and root canal therapy) was expected to be $<30 \mathrm{~min}$.

\section{Exclusion criteria}

The exclusion criteria were children or their families that could not agree, and their families were concerned that VR could have an impact on the eyes of the child and for other reasons that could interfere with wearing the VR glasses, such as those that required glasses for myopia. Since VR might cause motion sickness in some users, children were excluded with a history of motor diseases, motor nausea, or vomiting. Children with a history of epileptic or epileptic seizures were excluded, because there are some reports that VR has a theoretical risk of inducing seizures. Unpleasant treatment experience increases anxiety and pain during the following dental sessions, which results in increased pain 
perception. Therefore, in this study, subjects were excluded if they had a previous serious dental experience [27].

If a child had a serious fear or severe movement during the intervention, the trial was terminated immediately. Figure 1 shows the CONSORT Flow Diagram for the trial.

\section{Technical specifications}

HTC (Hsinchu, Taiwan, China)'s VIVE VR helmet was used, which is commercial, widely used, with a short delay time for video scenes, and is not prone to head vertigo. The VIVE is composed of 32 sensors for $360^{\circ}$ motion tracking, two $2160 \times 1200$ combined resolution AMOLED screens, and a 90- $\mathrm{Hz}$ refresh rate. The helmet was connected to an ASUS Game notebook with an Intel Core $\mathrm{i} 7-8820 \mathrm{~K}$ processor, 16-GB RAM, and an NVIDIA GeForce GTX 1070 graphics card. The virtual environment allowed the user to navigate naturally, which was created through a $110^{\circ}$ field of view for immersion.

\section{Procedure}

Patients were randomly allocated to two conditions using randomization software (STATA software version 15.1). Eligible children's parents or caregivers were informed about the trial by the anesthetists, and informed consent was obtained preoperatively. When they had agreed to participate in the study, personal medical data were collected by researchers and the baseline anxiety was assessed by CFSS-DS (T0 = time after signing the consent). Then, the anesthetist nurse randomly allocated children to the VR intervention or to the control group (children only received tell-show-do (TSD) as usual). Block randomization was performed based on the type of dental procedure: caries treatment, extraction of deciduous teeth, incision of abscess, and root canal therapy. After randomization, the VR intervention took place in a separate room under the guidance of the nurse anesthetist, and children in the TSD group were admitted to the other room. Both groups were treated by experienced pediatric dentists. Figure 2 shows an example of the dental procedure using HTC's VIVE helmet.

The assessment per time point was performed. FBRS was scored before intervention ( $\mathrm{T} 1=5 \mathrm{~min}$ before dental procedure) and remeasured at the moment of local anesthetic injection (T2). CFSS-DS and patient satisfaction (PS) scores were performed $5 \mathrm{~m}$ after the end of treatment (T3). Because VR intervention could cause adverse events, dizziness, nausea, vomiting, and epilepsy, they were followed-up during treatment. In addition, changes in heart rate and peripheral capillary oxygen

\section{CONSORT Flow Diagram}

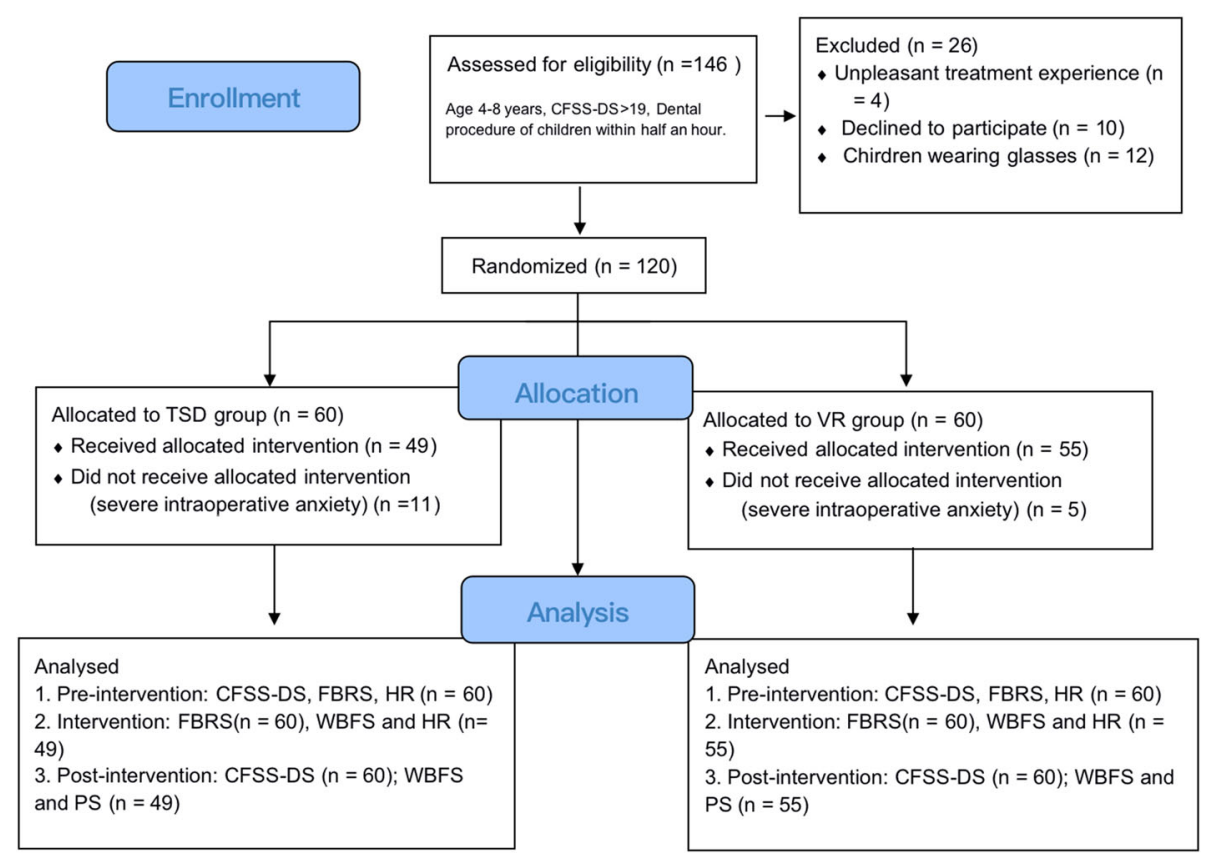

Fig. 1 CONSORT flow diagram for the randomized trial. CFSS-DS, Children's Fear Survey Schedule-Dental Subscale; TSD, tell-show-do; VR, virtual reality; FBRS, Frankl Behavior Rating Scale; WBFS, Wong Baker FACES Pain Rating Scale; HR, heart rate; PS, patient satisfaction 


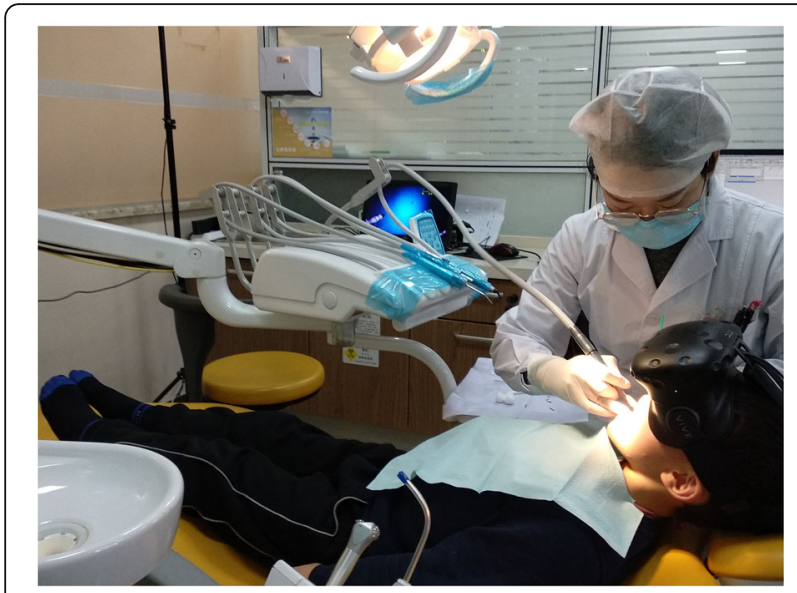

Fig. 2 A scene in which HTC's VIVE VR helmet is being used during a dental procedure

saturation between both groups before, during, and after dental treatment were measured.

\section{VR intervention}

Before the dental procedure, the patient was shown the corresponding scenes, specific inducers, and background music that was developed with psychologists, which could attract their attention and relax them. The children lay down on the dental chair and did not shake their heads left and right, which caused the treatment to be interrupted. The nurse anesthetist put the helmet and earphones on the children, who entered a virtual world where they could follow a set route and watch different information expressed in the scenes. The story began in a shallow sea world with a soft environment. The undersea world could only be saved when the undersea creatures shared their most precious things to nourish a rare pearl. First, "I" am in a shell, and a little elf introduces the creatures of the sea and their precious spirits. Second, a sea anemone protected the clown fish when the clown fish reduces the surface material of the anemone, and they shared this precious friendship by helping each other (Fig. 3a). Then, the children were introduced to the ancient precious and tenacious vitality of animals: turtles (Fig. 3b), parrot fish solidarity (Fig. 3c), and the dolphin's helpful spirit (Fig. 3d). Scenes were switched for the children to introduce a beautiful and dangerous jellyfish, which shared its valuable ability to predict storms (Fig. 3e). Finally, the pearl was born from the precious spiritual nourishment from thousands of marine creatures and the undersea world was restored to its former peace and tranquility (Fig. 3f). In addition, the virtual environment was displayed on the ASUS
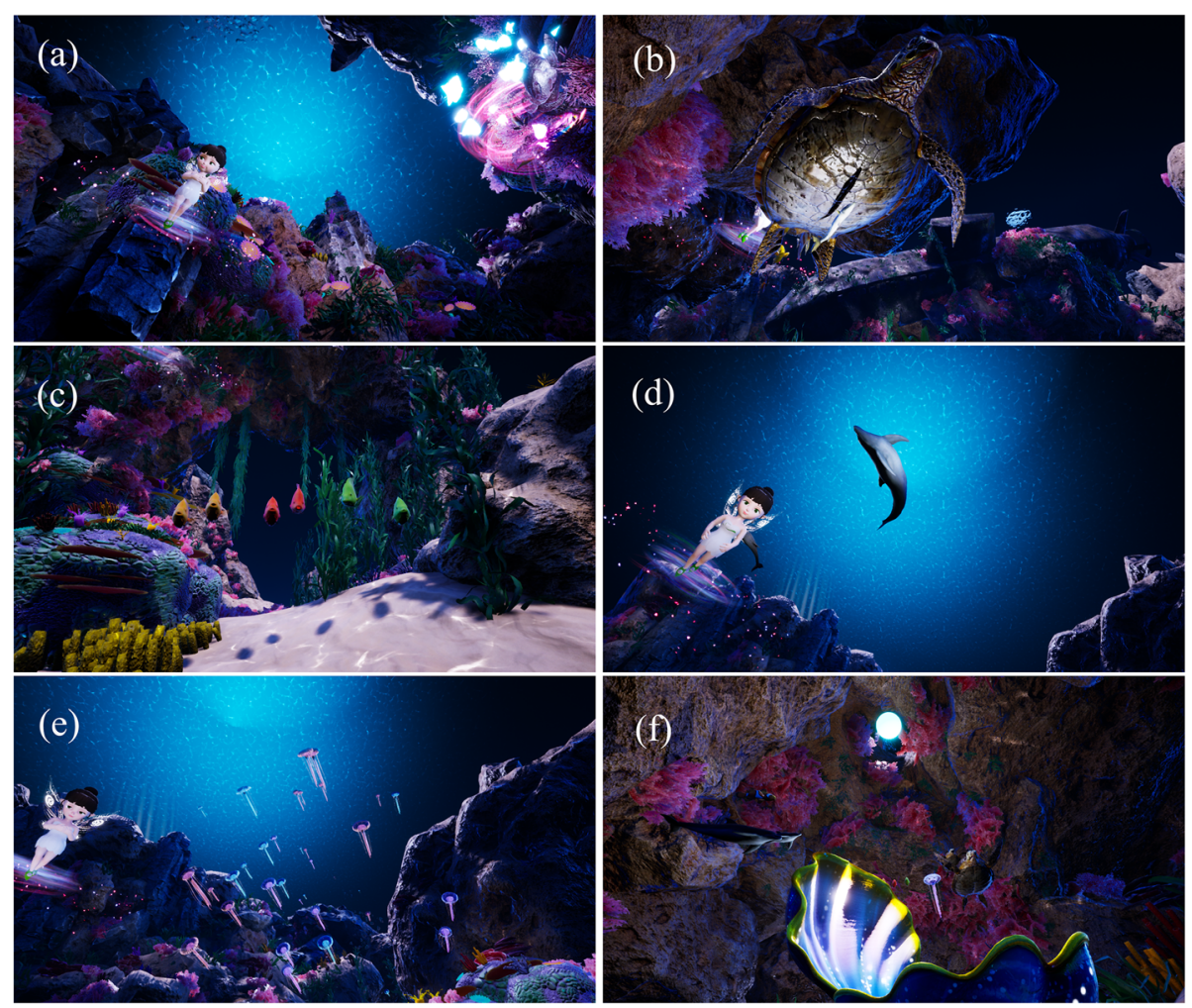

Fig. 3 Screenshot of custom scenario 
notebook, and therefore, the accompanying families could see what the child was viewing.

\section{Primary outcomes}

The primary outcomes were CFSS-DS, WBFS, and FBRS in the VR group, compared with those in the TSD group. The CFSS-DS was monitored at T0 and T3, while FBRS was evaluated at T2 and T3, and WBFS (score was from 0 to $10 ; 0=$ no pain, $10=$ extreme pain) was recorded at $\mathrm{T} 2$ and $\mathrm{T} 3$ points.

\section{Statistical analyses}

Data were analyzed using SPSS software version 22 (IBM, Chicago, USA). The statistically significant difference was set at $p<0.05$. A Chi-squared test was used to assess gender difference, ASA physical status, type of dental procedure, and local anesthetic between both groups. All quantitative variables were presented as mean \pm standard deviation, and the analysis of variance or a nonparametric test was performed for comparisons according to the data distribution. Mann-Whitney $U$ tests were used to compare the downward trend for the level of anxiety and FBRS.

\section{Results}

The trial was composed of 25 girls and 35 boys in the VR group and 32 girls and 28 boys in the TSD group, respectively. The mean ages in the VR and TSD groups were $5.59 \pm 0.92$ and $5.66 \pm 0.99$ years, $p=0.69$. Similarly, there were no significant differences between both groups in the means for gender, ASA physical status, type of dental procedure, and location and type of dental procedure (Pearson's Chi-squared test, $p>$ 0.05; Table 1).

The mean anxiety scores decreased significantly after VR distraction. In the VR group, the CFSS-DS was 34.17 \pm 5.81 before the intervention, which decreased to 24.77 \pm 6.98 after VR distraction. In the TSD group, the anxiety scores were $34.08 \pm 8.42$ and $27.98 \pm 7.41$, respectively $(n=60)$. The anxiety score between VR intervention and TSD were statistically different after a dental procedure (Table 2). Table 2 shows the downward trend of variations in anxiety scores between both groups and the differences were statistically significant.

The Mann-Whitney $U$ tests of FBRS for the VR group in the pre-intervention were $2(2,3)$. Similarly, the T2 of VR distraction treatment were $3(3,4)$, which represented that VR distraction improved patient compliance. In the control group, the FBRS before intervention and the time of the maximum procedure pain were $2(2,3)$ and $3(2,3)$, respectively. This indicated that VR increased compliance ( $p=0.02$; Table 2$)$.

Five children $(8.33 \%)$ in the VR group had severe intraoperative anxiety and stopped treatment in fear, compared with 11 cases $(18.33 \%)$ in the TSD group ( $p<$ 0.05). The CFSS-DS score of the children after the exclusion of the previous patient found that VR interference relative to the control group could significantly alleviate the anxiety of the children, $p<0.05$. The FBRS of both groups at $\mathrm{T} 2 \mathrm{had}$ no statistical difference.

Table 1 Patient and dental procedures

\begin{tabular}{|c|c|c|c|}
\hline & $\operatorname{VR}^{\mathrm{a}}(n=60, \%)$ & $\operatorname{TSD}^{\mathrm{b}}(n=60, \%)$ & $p$-value \\
\hline Age (years) & $5.59 \pm 0.92$ & $5.66 \pm 0.99$ & 0.69 \\
\hline \multicolumn{4}{|l|}{ Gender } \\
\hline Male & $35(58.33)$ & $28(46.67)$ & \multirow[t]{2}{*}{0.20} \\
\hline Female & $25(41.67)$ & $32(53.33)$ & \\
\hline \multicolumn{4}{|l|}{ ASA $^{\complement}$ physical status } \\
\hline 1 & $43(71.67)$ & $46(76.67)$ & \multirow[t]{2}{*}{0.53} \\
\hline$\|$ & $17(28.33)$ & $14(23.33)$ & \\
\hline \multicolumn{4}{|l|}{ Dental procedure } \\
\hline Caries treatment & $27(45.00)$ & $20(33.33)$ & \multirow[t]{4}{*}{0.63} \\
\hline Extraction of deciduous teeth & $12(20.00)$ & $15(25.00)$ & \\
\hline Incision of abscess & $11(18.33)$ & $13(21.67)$ & \\
\hline Root canal therapy & $10(16.67)$ & $12(20.00)$ & \\
\hline \multicolumn{4}{|l|}{ Local anesthetic } \\
\hline Primacaine & $48(80.00)$ & $46(76.67)$ & \multirow[t]{2}{*}{0.39} \\
\hline Not used & $12(20.00)$ & $14(23.33)$ & \\
\hline
\end{tabular}


Table 2 Anxiety, pain, PS, and time of dental procedure in both groups

\begin{tabular}{|c|c|c|c|c|c|c|}
\hline & $\operatorname{VR}^{\mathrm{a}}(n=60)$ & $\operatorname{TSD}^{\mathrm{b}}(n=60)$ & $p$-value & VR $(n=55)$ & TSD $(n=49)$ & $p$-value \\
\hline \multicolumn{7}{|l|}{ Anxiety } \\
\hline \multicolumn{7}{|l|}{ CFSS-DS $^{\mathrm{C}}$} \\
\hline Pre-intervention (T0) & $34.17 \pm 5.81$ & $34.08 \pm 8.42$ & 0.95 & $33.15 \pm 4.82$ & $31.45 \pm 5.97$ & 0.11 \\
\hline Post-intervention (T3) & $24.77 \pm 6.98$ & $27.98 \pm 7.41$ & $0.02^{*}$ & $23.34 \pm 5.23$ & $25.43 \pm 5.20$ & $<0.05^{*}$ \\
\hline Downtrend (T0-T3) & $8(7,11)$ & $5(5,7)$ & $<0.001^{*}$ & $8(7,12)$ & $5(5,7)$ & $<0.001^{*}$ \\
\hline \multicolumn{7}{|l|}{$\mathrm{FBRS}^{\mathrm{d}}$} \\
\hline $\mathrm{T} 1$ & $2(2,3)$ & $2(2,3)$ & 0.26 & $2(2,3)$ & $2(2,3)$ & 0.12 \\
\hline $\mathrm{T} 2$ & $3(3,4)$ & $3(2,3)$ & $0.02^{*}$ & $3(3,4)$ & $3(3,3)$ & 0.11 \\
\hline \multicolumn{7}{|l|}{ Pain } \\
\hline \multicolumn{7}{|l|}{ WBFS $^{e}$} \\
\hline T2 (observed) & & & & $1.58 \pm 1.08$ & $2.86 \pm 0.96$ & $<0.001^{*}$ \\
\hline T3 (observed) & & & & $1.62 \pm 1.13$ & $3.59 \pm 1.19$ & $<0.001^{*}$ \\
\hline $\mathrm{PS}^{f}(\mathrm{~T} 3$, score 0-100) & & & & $88.33 \pm 7.15$ & $76.78 \pm 8.49$ & $<0.001^{*}$ \\
\hline \multicolumn{7}{|l|}{ Length of dental procedure $(\mathrm{m})$} \\
\hline T1 to T3 & & & & $19.02 \pm 5.32$ & $27.80 \pm 10.40$ & $<0.001^{*}$ \\
\hline Caries treatment & & & & $19(16,22)$ & $30(25,30)$ & $<0.001^{*}$ \\
\hline Extraction of deciduous teeth & & & & $14.75 \pm 2.77$ & $19.93 \pm 9.01$ & 0.07 \\
\hline Incision of abscess & & & & $22.40 \pm 3.89$ & $26.09 \pm 6.80$ & 0.15 \\
\hline Root canal therapy & & & & $23.57 \pm 4.39$ & $42.43 \pm 8.40$ & $<0.001^{*}$ \\
\hline
\end{tabular}

${ }^{\mathrm{a} V R}$ virtual reality group

${ }^{\mathrm{b}}$ TSD tell-show-do group

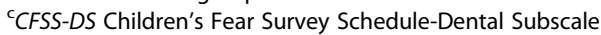

${ }^{\mathrm{d}}$ FBRS Frankl Behavior Rating Scale

${ }^{\mathrm{e}}$ WBFS Wong Baker FACES Pain Rating Scale

${ }^{f} P S$ Patient satisfaction

$T 0$, signature of informed consent statement; $T 1$, before intervention; $T 2$, the moment of local anesthetic injection; $T 3$, the end of treatment

${ }^{*} p$-value $<0.05$ statistically significant

During the operation, the pain score of the VR group $(1.58 \pm 1.08)$ was lower than that of the control group $(2.86 \pm 0.96)$. In addition, the results showed that the VR intervention at the end of treatment, related to the control of operation pain, worked best $(p<0.001)$ in the patients. Comparing the length of the dental procedure, the VR group $(19.02 \pm 5.32 \mathrm{~min})$ had a shorter treatment time than the control group $(27.80 \pm 10.40 \mathrm{~min})$. The results of this trial indicated the decreased treatment time was particularly significant in carie treatment and root canal therapy and was statistically significant $(p<0.001)$. Table 2 shows that the overall PS of the dental procedure with VR intervention $(88.33 \pm 7.15)$ was significantly higher than the TSD group $(76.78 \pm 8.49)$.

After monitoring the physiological signs, the VR group had decreased heart rates and the control group had the opposite $(p<0.05$; Fig. 4$)$. There was no significant difference in the $\mathrm{SPO}_{2}$, which was detected before and after the intervention between both groups.

\section{Discussion}

Our group has been engaged in oral-related sedation and analgesia for a long time; therefore, we considered whether new methods could be used to relieve the DA in this group of children [28-30]. Therefore, this trial focused on the effectiveness of compliance changes during VR distraction in 4-8-year-old children during a short invasive dental treatment [6]. The results of this trial supported that VR was associated with a larger decrease in behavioral avoidance compared with TDS intervention. The anxiety score of both groups before and after the intervention was monitored, and the VR group decreased more than the control group; however, the compliance score of the children increased. Aminabadi et al. reported that VR eyeglasses successfully decreased pain perception and the anxiety state during dental treatment in 4-6-year-old children [31]. Similarly, Shetty observed that VR distraction could be used as a successful behavior modification method in 5-8-year-old children that underwent short invasive dental treatments [32]. Therefore, this trial and references supported that immersion in a virtual environment could help to control DA, improve compliance, and relieve pain during pediatric dental treatment in children [31, 32]. Researchers showed that the effects of VR techniques on pain perception were beyond simple distraction [33]. In addition, by 


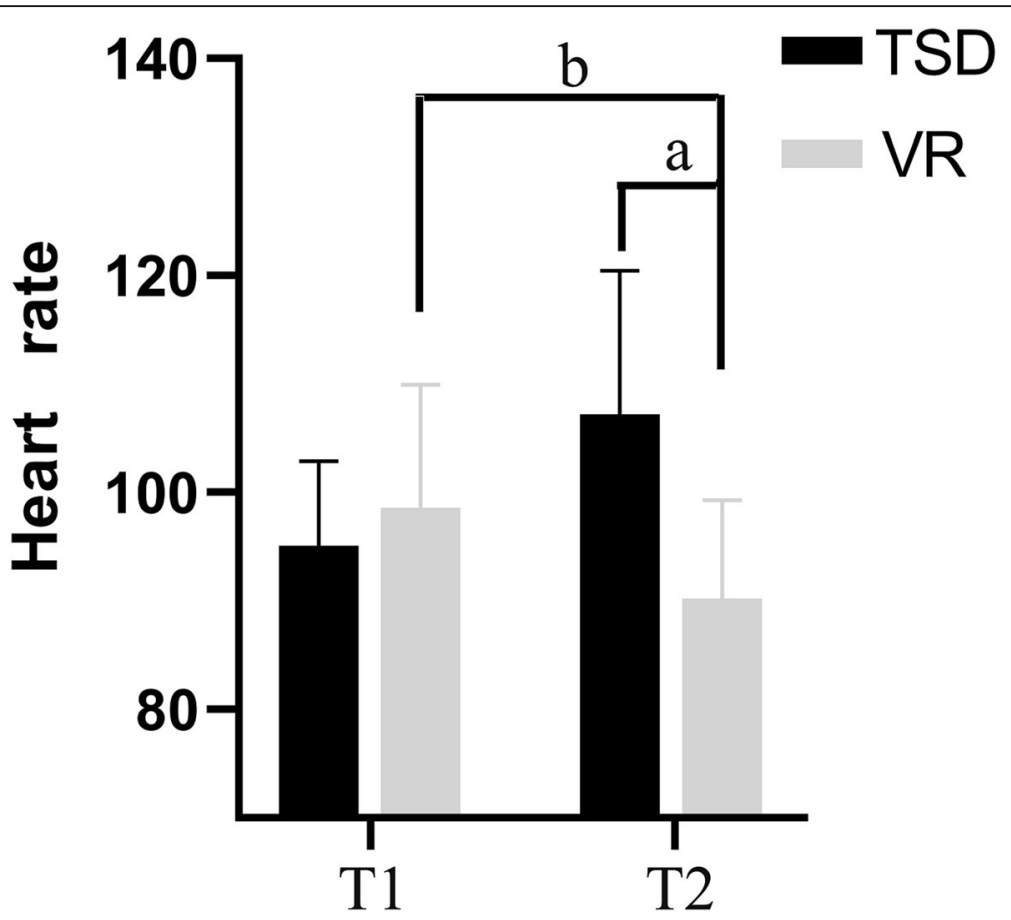

Fig. 4 Changes in heart rate before and during the dental treatment between both groups. VR, virtual reality group; TSD, tell-show-do group; T1, 5 min before dental procedure; T2, the moment of local anesthetic injection. ${ }^{a, b} p$-value $<0.05$

diverting attention from an unpleasant environment setting to a pleasant and absorbing virtual world, VR diminished the patient's physical pain experience [10, 34, 35]. By relieving anxiety and reducing pain, children cooperated better with the treatments, which included caries treatment and root canal therapy.

In addition, the treatment time for the VR group was significantly shorter than the control group. In a previous clinical treatment, general anesthesia by inhaling sevoflurane was an invasive medical method that has been used on most children, who had difficulty in adapting to TSD behavioral induction. Some children might have received delayed treatment because of family concerns about general anesthesia or their lack of cooperation with behavioral induction, which resulted in poor prognosis and long-term tooth problems. This trial suggested that the customized VR content applied in this study allowed children to be treated as quickly as possible and might reduce the frequency of patients seeking medical treatment and reduce the number of outpatients. In China, the ratio of health workers to people is significantly lower than the global average, especially pediatricians [36]. This could be beneficial for doctors and patients.

This trial has several limitations. First, the scales for anxiety and pain in children were relatively single, different clinometric tools, and assessments were not included. Second, other factors that affect children's behavior were not accounted for. Some researchers reported that several factors, such as age, gender, type of dental treatment, parental anxiety, and socioeconomic status were associated with anxiety should be assessed, because these might influence the efficacy of VR [37]. The evidence reported that older children considered the VR technique as a very simple game, and they had a have a lower level of distraction [33]. This study identified five children who were uncomfortable with VR distraction and terminated the trial, considering that some of them were possible terminated for these reasons. But the average age analysis of the five children was not statistically significant. In addition, their anxiety scores were $>35$ before and after treatment. Third, the pedodontists and the patients were not blinded to the interventions due to the apparent difference between both groups. During future work, the deficiency could be overcome by watching different VR animations in different groups. Fourth, the VR in this trial only had one animation content, which might be considered a limitation, because the stimuli that trigger DA might differ for each individual. Based on the current data that uses VR, anxiety score, and mobile internet APP to collect family members' awareness and anxiety about dental diseases, to achieve fewer generic intervention scenarios the next step could be hierarchical customization of VR content. In addition, VR should improve and its use increased in the children's department of stomatology. Finally, a set 
of intelligent biofeedback mechanisms should be formed to achieve closed-loop control of anxiety and pain in children; therefore, children will receive rapid, timely, and comfortable oral treatment.

This trial focused on the effectiveness of compliance changes in VR distraction in 4-8-year-old children during short-term invasive dental procedures. The VR distraction used nonintrusive methods; therefore, the children's parents or caregivers have not been concerned that general anesthesia might affect intelligence and learning ability. The adverse effects on vision and hearing have not been reported in this study and literature [31, 38-40]. Even with repeated dental treatments, parents and children are much more receptive to other methods.

\section{Acknowledgements}

The authors would like to thank the pedodontists of the Children's Stomatology of the Stomatological Hospital of the Chongqing Medical University for their great help.

\section{Authors' contributions}

LR and NZ made a common contribution. LR: collection of data, drafting of the manuscript, and final approval of submitted manuscript. NZ: analysis and interpretation of data, drafting of the manuscript, and final approval of submitted manuscript. LF: collection of data and final approval of submitted manuscript. PZ: collection of data and final approval of submitted manuscript. CZ: interpretation of data and final approval of submitted manuscript. CY: conception and design, drafting and revision of the manuscript, and final approval of submitted manuscript.

\section{Funding}

This trial was supported by the Research Project of Chongqing Municipal Public Health Bureau, China (2017ZDXM017). To approve that the author gave smaller drug interventions to dental procedure in children is the role of the funding body in the study.

\section{Availability of data and materials}

The ethical approval does not permit the sharing of the entire data that we have acquired, but the information required is already provided in the main manuscript.

\section{Declarations}

\section{Ethics approval and consent to participate}

The trial followed the Declaration of Helsinki on medical protocol and ethics and the Ethical Review Board of the Stomatological Hospital of Chongqing Medical University approved the trail. Written and verbal consent was obtained from all participants before the start of VR distraction.

\section{Competing interests}

The authors declare that they have no competing interests.

\section{Author details}

${ }^{1}$ Department of Anesthesiology, Stomatological Hospital of Chongqing Medical University, Chongqing, China. ${ }^{2}$ Chongqing Key Laboratory of Oral Diseases and Biomedical Sciences, Chongqing, China. ${ }^{3}$ Chongqing Municipal Key Laboratory of Oral Biomedical Engineering of Higher Education, Chongqing, China.

Received: 8 September 2020 Accepted: 13 August 2021 Published online: 23 August 2021

\section{References}

1. Vagnoli L, Bettini A, Amore E, De Masi S, Messeri A. Relaxation-guided imagery reduces perioperative anxiety and pain in children: a randomized study. Eur J Pediatr. 2019;178(6):913-21. https://doi.org/10.1007/s00431-01903376-x.

2. Voepel-Lewis T, Malviya S, Tait AR. A prospective cohort study of emergence agitation in the pediatric post anesthesia care unit. Anesth Analg. 2003;96(6):1625-30. https://doi.org/10.1213/01.ane.0000062522.21048. 61.

3. Cianetti S, Lombardo G, Lupatelli E, Pagano S, Abraha I, Montedori A, et al. Dental fear/anxiety among children and adolescents. A systematic review. Eur J Paediatr Dent. 2017;18(2):121-30. https://doi.org/10.23804/ejpd.2017.1 8.02.07.

4. Mathur J, Diwanji A, Sarvaiya B, Sharma D. Identifying dental anxiety in children's drawings and correlating it with Frankl's Behavior Rating Scale. Int J Clin Pediatr Dent. 2017;10(1):24-8. https://doi.org/10.5005/jp-journals-1 0005-1401.

5. Alshoraim MA, El-Housseiny AA, Farsi NM, Felemban OM, Alamoudi NM, Alandejani AA. Effects of child characteristics and dental history on dental fear: cross-sectional study. BMC Oral Health. 2018;18(1):33. https://doi.org/1 0.1186/s12903-018-0496-4

6. Zhang C, Huang GJ, Yu C. The effect of general anesthesia for ambulatory dental treatment on children in Chongqing, Southwest China. Paediatr Anaesth. 2017:27(1):98-105.

7. Malloy K, Milling LS. The effectiveness of virtual reality distraction for pain reduction: a systematic review. Clin Psychol Rev. 2010;30(8):1011-8.

8. Li A, Montaño Z, Chen VJ, Gold JI. Virtual reality and pain management: current trends and future directions. Pain Manag. 2011;1(2):147-57. https:// doi.org/10.2217/pmt.10.15.

9. Shin H, Kim K. Virtual reality for cognitive rehabilitation after brain injury: a systematic review. J Phys Ther Sci. 2015;27:2999-3002.

10. Maples-Keller JL, Yasinski C, Manjin N, Rothbaum BO. Virtual reality-enhanced extinction of phobias and post-traumatic stress. Neurotherapeutics. 2017;14(3): 554-63. https://doi.org/10.1007/s13311-017-0534-y.

11. Morris LD, Louw QA, Crous LC. Feasibility and potential effect of a low-cost virtual reality system on reducing pain and anxiety in adult burn injury patients during physiotherapy in a developing country. Burns. 2010;36(5): 659-64. https://doi.org/10.1016/j.burns.2009.09.005.

12. Tashijan VC, Mosadeghi S, Howard AR, Lopez M, Dupuy T, Reid M, et al. Virtual reality for management of pain in hospitalized patients: results of a controlled trial. JMIR Ment Health. 2017:4(1):e9.

13. Chirico A, Lucidi F, De Laurentiis $M$, et al. Virtual reality in health system: beyond entertainment. A mini-review on the efficacy of VR during cancer treatment. J Cell Physiol. 2016;231:275-87.

14. Khor WS, Baker B, Amin K, et al. Augmented and virtual reality in surgery the digital surgical environment: applications, limitations and legal pitfalls. Ann Transl Med. 2016:4:454.

15. Wiederhold BK, Riva G, Gutierrez-Maldonado J. Virtual reality in the assessment and treatment of weight-related disorders[J]. Cyberpsychol Behav Soc Netw. 2016;19:67.

16. Sato K, Fukumori S, Matsusaki T, Maruo T, Ishikawa S, Nishie H, et al. Nonimmersive virtual reality mirror visual feedback therapy and its application for the treatment of complex regional pain syndrome: an openlabel pilot study. Pain Med. 2010;1(4):622-9.

17. Sarig-Bahat $H$, Weiss $P L$, Laufer $Y$. Neck pain assessment in a virtual environment. Spine (Phila Pa 1976). 2010:35(4):E105-12.

18. Triberti S, Repetto C, Riva G. Psychological factors influencing the effectiveness of virtual reality-based analgesia: a systematic review. CyberpsycholBehav Soc Netw. 2014;17:335-45.

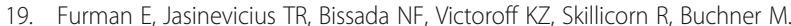
Virtual reality distraction for pain control during periodontal scaling and root planing procedures. J Am Dent Assoc. 2009;140(12):1508-16. https:// doi.org/10.14219/jada.archive.2009.0102.

20. Garrett B, Taverner T, Masinde W, Gromala D, Shaw C, Negraeff M. A rapid evidence assessment of immersive virtual reality as an adjunct therapy in acute pain management in clinical practice. Clin J Pain. 2014;30(12):1089-98. https://doi.org/10.1097/AJP.0000000000000064.

21. Gold J, Kim SH, Kant AJ, Joseph MH, Rizzo AS. Effectiveness of virtual reality for pediatric pain distraction during i.v. placement. CyberPsychol Behav. 2006;9(2):207-12. https://doi.org/10.1089/cpb.2006.9.207.

22. Hoffman HG, Doctor JN, Patterson DR, Carrougher GJ, Furness TA. Virtual reality as an adjunctive pain control during burn wound care in adolescent patients. Pain. 2000;85(1-2):305-9. https://doi.org/10.1016/50304-3959(99)002 75-4. 
23. Gujjar KR, van Wijk A, Kumar R, de Jongh A. Efficacy of virtual reality exposure therapy for the treatment of dental phobia in adults: a randomized controlled trial. J Anxiety Disord. 2019;62:100-8. https://doi. org/10.1016/j.janxdis.2018.12.001.

24. Nuvvula S, Alahari S, Kamatham R, Challa RR. Effect of audiovisual distraction with $3 \mathrm{D}$ video glasses on dental anxiety of children experiencing administration of local analgesia: a randomised clinical trial. Eur Arch Paediatr Dent. 2015;16(1):43-50.

25. Niharika P, Reddy NV, Srujana P, Srikanth K, Daneswari V, Geetha KS. Effects of distraction using virtual reality technology on pain perception and anxiety levels in children during pulp therapy of primary molars. J Indian Soc Pedod Prev Dent. 2018;36(4):364-9. https://doi.org/10.4103/JISPPD.JISPPD_1158_17.

26. Lu JX, Yu DS, Luo W, Xiao XF, Zhao W. Development of Chinese version of children's fear survey schedule-dental subscale. Zhonghua Kou Qiang Yi Xue Za Zhi. 2011:46(4):218-21.

27. Nichols $\mathrm{S}$, Patel $\mathrm{H}$. Health and safety implications of virtual reality: a review of empirical evidence. Appl Ergon. 2020;33(3):251-71. https://doi.org/10.101 6/s0003-6870(02)00020-0.

28. Zhao N, Deng F, Yu C. Anesthesia for pediatric day-case dental surgery: a study comparing the classic laryngeal mask airway with nasal trachea intubation. J Craniofac Surg. 2014;25(3):e245-8. https://doi.org/10.1097/SCS. 0000000000000547.

29. Xi MY, Li SS, Zhang C, Zhang L, Wang T, Yu C. Nalbuphine for analgesia after orthognathic surgery and its effect on postoperative inflammatory and oxidative stress: a randomized double-blind controlled trial. J Oral Maxillofac Surg. 2020;78(4):528-37. https://doi.org/10.1016/j.joms.2019.10.017.

30. Zhao N, Wu YJ, Yu C. Effect of intravenous nalbuphine on emergence agitation in children undergoing dental surgery under sevoflurane anesthesia. Int J Exp Med. 2018;11(9):10215-22.

31. Asl Aminabadi N, Erfanparast L, Sohrabi A, Ghertasi Oskouei S, Naghili A. The impact of virtual reality distraction on pain and anxiety during dental treatment in 4-6 year-old children: a randomized controlled clinical trial. J Dent Res Dent Clin Dent Prospects. 2012;6(4):117-24. https://doi.org/10. 5681/joddd.2012.025.

32. Shetty $V$, Suresh $L R$, Hegde AM. Effect of virtual reality distraction on pain and anxiety during dental treatment in 5 to 8 year old children. J Clin Pediatr Dent. 2019:43(2):97-102. https://doi.org/10.17796/1053-4625-43.2.5.

33. Das DA, Grimmer KA, Sparon AL, MC Rae SE, Thomas BH. The efficacy of playing a virtual reality game in modulating pain for children with acute burn injuries: a randomized controlled trail. BMC Pediatr. 2005;5(1):1. https:// doi.org/10.1186/1471-2431-5-1.

34. Hoffman HG, Richards TL, Coda B, Bills AR, Blough D, Richards AL, et al. Modulation of thermal pain related brain activity with virtual reality: evidence from FMRI. Neuroreport. 2004;15(8):1245-8. https://doi.org/10.1 097/01.wnr.0000127826.73576.91.

35. Nilson S, Finnstrom B, Kokinsky E, Enskar K. The use of virtual reality for needle related procedural pain and distress in children and adolescents in a pediatric oncology unit. Eur J Oncol Nurs. 2009;13(2):102-9. https://doi.org/1 0.1016/j.ejon.2009.01.003.

36. Hu KJ, Sun ZZ, Rui YJ, Mi JY, Ren MX. Shortage of paediatricians in China. Lancet. 2014;383(9921):954. https://doi.org/10.1016/S0140-6736(14)60482-7.

37. Prabhaker AR, Marwah N, Raju OS. A comparison between audio and audiovisual distraction techniques in managing anxious pediatric dental patients. J Indian Soc Pedod Prev Dent. 2007;25(4):177-82.

38. López-Valverde N, Muriel Fernández J, López-Valverde A, Valero Juan LF, Ramírez JM, Flores Fraile J, et al. Use of virtual reality for the management of anxiety and pain in dental treatments: systematic review and metaanalysis. J Clin Med. 2020;9(4):1025. https://doi.org/10.3390/jcm9041025.

39. Lambert V, Boylan P, Boran L, Hicks P, Kirubakaran R, Devane D, et al. Virtual reality distraction for acute pain in children. Cochrane Database Syst Rev. 2020;10(10):CD010686.

40. Eijlers R, Legerstee JS, Dierckx B, Staals LM, Berghmans J, van der Schroeff $M P$, et al. Development of a virtual reality exposure tool as psychological preparation for elective pediatric day care surgery: methodological approach for a randomized controlled trial. JMIR Res Protoc. 2017;6(9):e174. https://doi.org/10.2196/resprot.7617.

\section{Publisher's Note}

Springer Nature remains neutral with regard to jurisdictional claims in published maps and institutional affiliations.

\section{Ready to submit your research? Choose BMC and benefit from}

- fast, convenient online submission

- thorough peer review by experienced researchers in your field

- rapid publication on acceptance

- support for research data, including large and complex data types

- gold Open Access which fosters wider collaboration and increased citations

- maximum visibility for your research: over $100 \mathrm{M}$ website views per year

At BMC, research is always in progress.

Learn more biomedcentral.com/submissions 